Article

\title{
SolarSPELL Assessment: Impact of a Solar-Powered Digital Library as a Teaching-Learning Resource on Climate Change
}

\author{
Laura Hosman ${ }^{1}\left(\mathbb{D}\right.$, Marcela Georgina Gómez Zermeño ${ }^{2, *(D)}$ and Lorena Alemán de la Garza ${ }^{2}$ (D) \\ 1 School for the Future of Innovation in Society (SFIS), Arizona State University, Tempe, AZ 85287, USA; \\ laura.hosman@asu.edu \\ 2 School of Humanities and Education, Tecnologico de Monterrey, Monterrey 64849, Mexico; \\ lorena.aleman@tec.mx \\ * Correspondence: marcela.gomez@tec.mx
}

Received: 6 July 2020; Accepted: 7 August 2020; Published: 17 August 2020

check for updates

\begin{abstract}
Inclusive and quality education can provide nations with the tools to solve global problems. However, some barriers prevent equal access to this education. These obstacles include the lack of basic resources such as electricity and internet availability, which prevents appropriate training in the skills necessary for sustainable community development. Therefore, we have responded with the Solar-Powered Educational Learning Library (SolarSPELL) initiative, which offers a solar-powered digital library and provides an internet-like experience through its offline WiFi network. This educational innovation has been implemented in rural schools across the Pacific Islands, including in some of the more remote islands of Fiji, an area strongly affected by climate change. The objective of the study was to understand the impact of SolarSPELL on teaching and learning about climate change in the schools where it was implemented. This research used a case study method in which quantitative tools were applied to understand the characteristics of the schools and the impact of this educational innovation. The results showed that the SolarSPELL library was an impactful pedagogical resource in the schools where it was implemented. It served as support for teachers and motivated the students, promoted the democratization of knowledge in vulnerable areas, and provided appropriate educational resources to generate knowledge about problem-solving actions that can respond to climate change. The importance of this educational innovation lies in presenting strategies and best practices that help improve the quality of education, making it more inclusive and eliminating barriers to the acquisition of knowledge.
\end{abstract}

Keywords: sustainability; climate change; SolarSPELL; inclusion; educational innovation; higher education

\section{Introduction}

Education is the foundation for improving people's lives and achieving sustainable development, so access to inclusive education can provide people with the tools to generate solutions to address the world's problems [1]. Globally, efforts are being made to achieve inclusive education and improve student learning [2]. Inclusive education implies that each student should be provided with a quality education according to their abilities, removing barriers to participation in learning situations so that the students and their families belong to the school community [3]. However, inclusive education has not yet been achieved, in reality, so that all students might access the spaces where they can learn and obtain those basic skills that gain them a quality life in a world where no one is left behind for social, individual, or group reasons [4].

Sustainable development is integrated into the spirit of inclusive education. The concept of sustainability includes approaches, methods, and solutions to solve problems and promote education 
that supports equality in educational environments [5,6]. Previous studies show that the use of Information and Communication Technologies (ICT) tools facilitate the construction of more inclusive and quality education, diminishing the gaps among students due to gender, disabilities, and the competencies of their teachers, among others [7-9].

When considering the relevance of continuing research to improve the quality of education and promote knowledge about inclusive human development, one must remember that there are still places on the planet that do not have basic elements necessary for the use of ICTs, such as electricity and the internet, especially in poor and rural areas [10]. For people who lack access to the necessary infrastructure of electricity and connectivity, the use of ICTs is not possible, so hardware like that developed for the Solar Powered Educational Learning Library (SolarSPELL) steps in to meet these needs [11]. This study presents the results of using the SolarSPELL digital library that provides offline WiFi access to relevant educational content, so that communities without access to the grid or theinternet, can connect and improve the digital skills of their inhabitants [12].

SolarSPELL helps to reduce the resource gaps that exclude vulnerable populations and prevent inclusive education. We designed this tool considering the needs of developing countries and their challenges, such as connectivity issues, extreme environmental conditions that affect traditional hardware, and the lack of electrical power, among others [13]. This research analyzes a case study in which best practices are presented for the study of climate change in rural schools in Fiji, where the use of SolarSPELL boosts inclusivity in one of the most environmentally vulnerable areas of the planet, improves the quality of people's lives, and provides opportunities to build resilience. Therefore, this study presents the results of implementing the SolarSPELL library in seven rural schools in Fiji to answer the following research question: How does SolarSPELL impact the process of teaching-learning about climate change issues in schools located in rural communities in Fiji?

\subsection{Education for Sustainable Development}

Education for sustainable development prepares people for actions to solve the problems that arise in their learning, their lives, and their work, taking as priority tasks the eradication of poverty, gender inequality, and the lack of environmental protection, among others [14]. The International Decade of Education for Sustainable Development 2005-2014 calls for countries to integrate education for sustainable development into educational strategies at all formative levels [15]. The primary competencies for sustainable development include communication, collaboration, critical thinking, innovation, and creativity, which must be integrated into the curricula that promote sustainability as a continuous process [16].

Previous studies related to education for sustainable development highlight the importance that institutions of higher education attach to molding the attitudes of future professionals toward sustainable development $[17,18]$. In a study conducted in Malaysia, 154 higher education students from five different universities were surveyed on their perceptions of sustainable development; these educational institutions provided these courses within their professional programs [19]. The questionnaire applied included three dimensions of sustainability, namely, social, environmental, and economical. The results showed that students think that each individual must take the necessary measures to curb global warming, that people are responsible for caring for the environment and its resources, and that environmental protection is important for the present and future of new generations. The study concluded that knowledge of the skills and values obtained through education for sustainable development is fundamental to developing these competencies in students, who will take on the mantle of achieving the vision of the Sustainable Development Goals (SDGs) by 2030 [19].

On the other hand, Istenic Starcic [20] indicates that there is a division between awareness of the concepts of sustainable development and student behaviors because the curricula are designed for awareness and not toward cultivating these behaviors. So, it is necessary to look for productive ways to connect experiences and practices and achieve superior levels of active learning. This requires innovative educational practices and the development of teacher competencies so that they can 
empower their students to become agents of change for sustainability [21]. Therefore, the studies encourage actions for the preparation of teachers and students to promote sustainable behavior at all levels of education.

\subsection{Teaching Climate Change}

As mentioned above, students become aware of the need to protect and care for the environment, so climate change becomes a fundamental topic in sustainable development programs [22]. Interest in climate change education has increased in recent years, and this discussion has emerged from higher education [23].

It is also important to address the issue of climate change in primary education, which is responsible for training the future generations, so these issues should be included in the school curricula [15]. Such education consists of understanding climate change, climate adaptation, and climate change mitigation, which is supported by reflection and commitment [15]. However, it has been found that teachers have difficulty understanding how to incorporate this approach into the classroom. The reasons depend on the context of their situations, so it is necessary to adapt each study to its local reality after understanding how climate change has been presented previously in the researcher's study area of interest [24].

The Pacific Islands are particularly vulnerable to the effects of climate change because of rising sea levels that threaten the coast and the deterioration of ecosystems and native forests, as well as the rising incidence of extreme weather events, making it crucial for their citizens to know how to protect the environment in these places [25]. So, given the context in which SolarSPELL has been implemented, this study explores the results of its use in the teaching-learning process from the viewpoint of its users.

\subsection{Digital Libraries as a Pedagogical Resource}

A digital library consists of databases that allow access to a large amount of information; however, these do not always fit the needs of primary school users nor consider how children organize their contents [26]. For Druin [27], the children's libraries provide the opportunity to offer various types of resources to strengthen teaching activities. To take advantage of this, the teachers must play active roles in selecting both the activities and the resources.

As a pedagogical resource, digital libraries have been used with the help of technologies to integrate educational activities that pursue the following objectives [28]:

- The social appropriation of knowledge through public communication and the popularization of science, technology, and innovation.

- Citizen science through collaborative research between scientific communities and citizens who participate voluntarily. Its objective is to generate knowledge and communicate best practices that lead to the democratization of information.

- Social innovation through applying knowledge to projects and working with organizations that facilitate the search for solutions to social problems, improve the quality of life of citizens, and reduce the vulnerability of communities.

\subsection{The SolarSPELL Offline Digital Library}

The SolarSPELL library is ultra-portable, ruggedized, and solar-powered: a plug-and-play kit, so that it can be brought anywhere and will function even under environmentally and infrastructurally challenging conditions. It was designed to adhere to an "open" mindset: open-source (Linux-based) software running the library, open access content populating the library, and open hardware comprising the library.

The library's hardware comprises a solar panel, waterproof plastic case, lithium-ion battery, voltage regulator, Micro USB to USB cords, a Raspberry Pi microcomputer (functioning as a server) and an SD memory card that houses the library's content and website, as well as the Raspberry Pi's 
operating system. Although plans are underway to develop a mass-producible version of the library, at present, SolarSPELLs are assembled twice per year by a team of (student-led) volunteers at Arizona State University, where an assembly line is formed, and approximately 100 library kits are assembled in a day. Figure 1, below, depicts a "SolarSPELL Build Day."
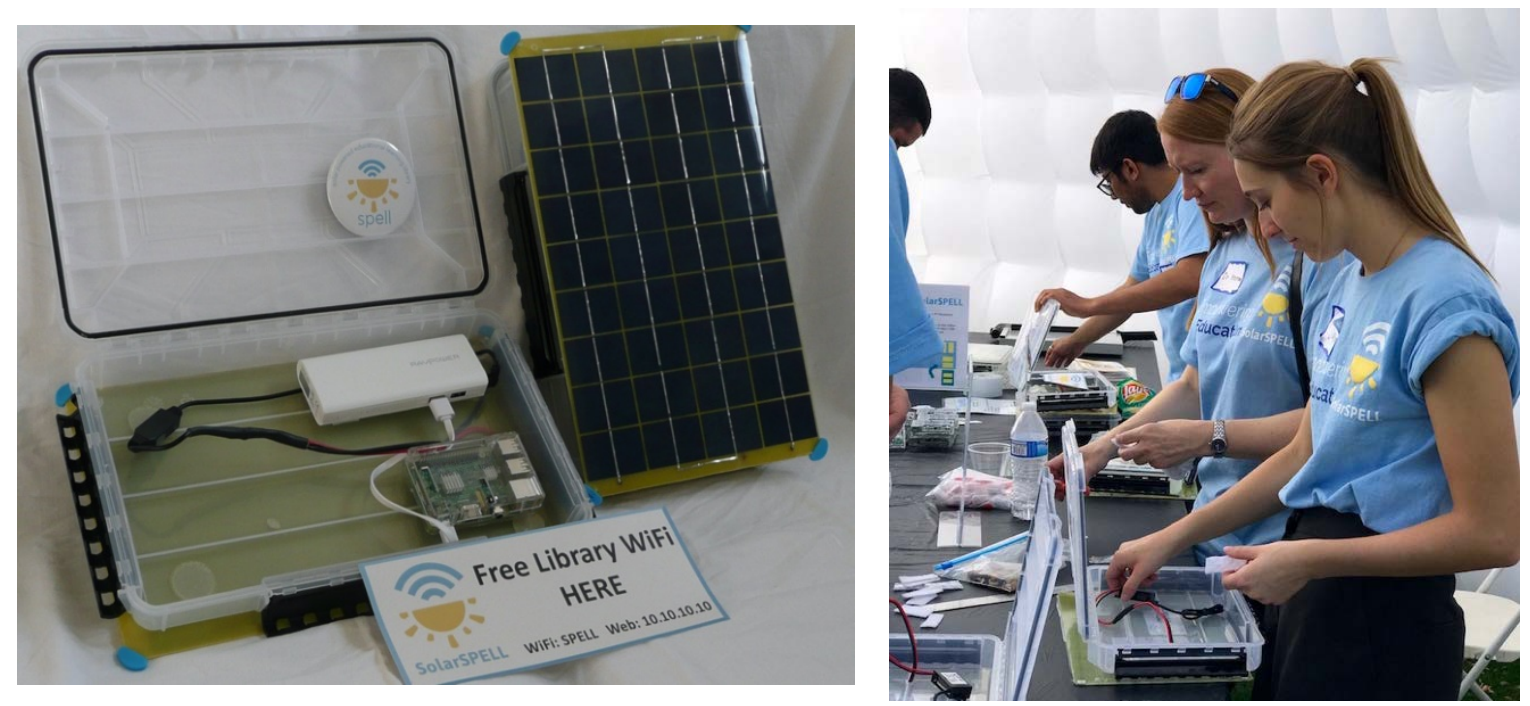

Figure 1. Assembling the SolarSPELL libraries, and the finished product: a SolarSPELL library.

Although the Build Day presents an opportunity for community involvement and awareness-raising about both the initiative and the global need for improved educational opportunities, it is not where the curation of the library's content takes place. The process of curating a localized library is extremely time-intensive, because resources must be selected considering local interest, national curriculum, and language, and must be done in partnership with local organizations, schools, and institutions.

The main digital component of the SolarSPELL is the library server, which generates an offline WiFi hotspot, to which any device with WiFi and a browser can connect. The library's content appears as a webpage, so once users are connected, they can freely surf the library's content-there are no passwords required, and no data fees for its use. All of the library's content is educational and open-access (or permission has been given to share it). Much of the content has been localized to the region of implementation.

The format of library resources has been standardized as pdf files, mp4 video/audio files, and html5 interactive modules or pages. This is done in the attempt to ensure that any device, anywhere, can open (stream or download) any file in the library without needing to download any software, because we anticipate that our users have no connectivity.

The objectives outlined above, focused upon social impact, were central to the creation of the SolarSPELL digital library. The library was developed by a team of academic-practitioners and university students, to be introduced to environmentally vulnerable communities [29] and used as pedagogical resources. This educational innovation was created to help overcome existing barriers to reliable, high-quality educational content in regions that lack access to the Internet and electricity.

The educational resources available to students in regions with limited resources are often outdated and donated by countries whose curricula and culture are not representative of the receiving populations. To address this challenge, we designed SolarSPELL's learning libraries to have particular regional content, providing teachers and students with the most relevant knowledge and skills for their communities. This open-access content is compiled into eight main categories of topics, including the creative arts, the environment, health and safety, language arts, local topics, mathematics, science, and reference tools [30]. 
All the technological tools that comprise the SolarSPELL digital library are solar-powered, and thus the classrooms and schools using it have access to a self-powered digital library that does not require internet connectivity or external electricity (see Figure 1, above). The SolarSPELL intends to be similar to a traditional library, in that it is curated to meet the needs of its users, organized by relevant categories, and ready for patrons to explore in a safe space. Because the library's resources are open access, the resources can be downloaded by any library user and shared freely. Updating the library means swapping out the existing SD card for a new SD card with the most up-to-date version of the library loaded on it: updating takes place entirely offline, because, again, we presume a situation of non-connectivity. In most cases, a new version of the library is distributed once per year, when the team returns for a new round of Train-The-Trainer training and impact evaluation.

The library was designed to mimic an online experience so that even in the absence of internet connectivity, and even for first-time website users, internet-ready skills can be taught. Along these same lines, and due to years of in-field observation, the inventors of the SolarSPELL library have opted to keep the library as simple and straightforward as possible: it does not presume that skillsets exist, which first-time internet users do not yet possess, but rather, works to develop those skillsets. To enable this skills development to happen, SolarSPELL both partners with local organizations and employs a Train-The-Trainer model, to ensure that the technology is never "dropped from the sky" with users left to figure things out on their own [31].

According to the literature analyzed, research into best practices that promote sustainable development and the study of climate change is necessary to achieve the SDGs and arrive at a quality education. However, one should not overlook the fact that not everyone has access to the things necessary for more inclusive education, so we present this case study and disclose the findings of the SolarSPELL initiative, which was implemented as a pedagogical resource to achieve these objectives in the most environmentally vulnerable communities.

\subsection{Context}

The Pacific Islands are considered globally as a barometer and first line of impact for climate change [32]. These particularly vulnerable island nations are at the intersection of vast and complex challenges: (1) they have the world's highest relative disaster risk; (2) climate change intensifies this risk, and (3) disasters challenge their economic resilience [33]. In addition to their geographical predisposition to extreme weather phenomena, the remote nature of these islands presents unique infrastructural challenges: Internet connectivity and current, relevant educational information remain inaccessible to most islanders in the rural Pacific. As a result, the people who face the adverse effects of climate change the most are the least equipped with the knowledge and adaptive practices to deal with the devastating impact on their communities [34].

Because of this reality, a group of higher education academic-practitioners has implemented in the last five years more than 365 SolarSPELL libraries in rural schools in eight countries located mainly in the Pacific Islands: Fiji, Samoa, Micronesia, Tonga, and Vanuatu; and also in eastern Africa: Comoros, Rwanda, and South Sudan [12,30].

In Fiji, the researchers implemented a pilot in fifteen rural primary schools, and this research reports on the evaluation of the results in a sampling of seven of these schools. All 15 schools had sent two instructors (one local teacher and one Peace Corps volunteer who taught in the school, hereafter referred to as volunteer) to a three-day training on the SolarSPELL digital library, which took place in August 2019. As SolarSPELL follows a train-the-trainer model, after this training, the teachers returned to the schools at which they taught, and became the trainers of others, on the SolarSPELL library.

The study in this article took place in February 2020, six months after the training had taken place. The schools participating in this study were the Rukuruku District School, Korokadi Primary School, Vunidawa Primary School, Natewa District School, Saint Mary's Primary School, Vuanisaiki Primary School, and Uluivalili College. The location of the schools is shown in Figure 2. The researchers were on-site in Fiji, traveling to and carrying out research at the participating schools for approximately 
two weeks' time. During this time, three researchers were in Fiji, one from Arizona State University and two from Tecnologico de Monterrey. While the SolarSPELL initiative resides at Arizona State University, the desire existed for an independent assessment, and its impact evaluation, and the director of the SolarSPELL initiative requested involvement from the academics and researchers at Tecnologico de Monterrey.

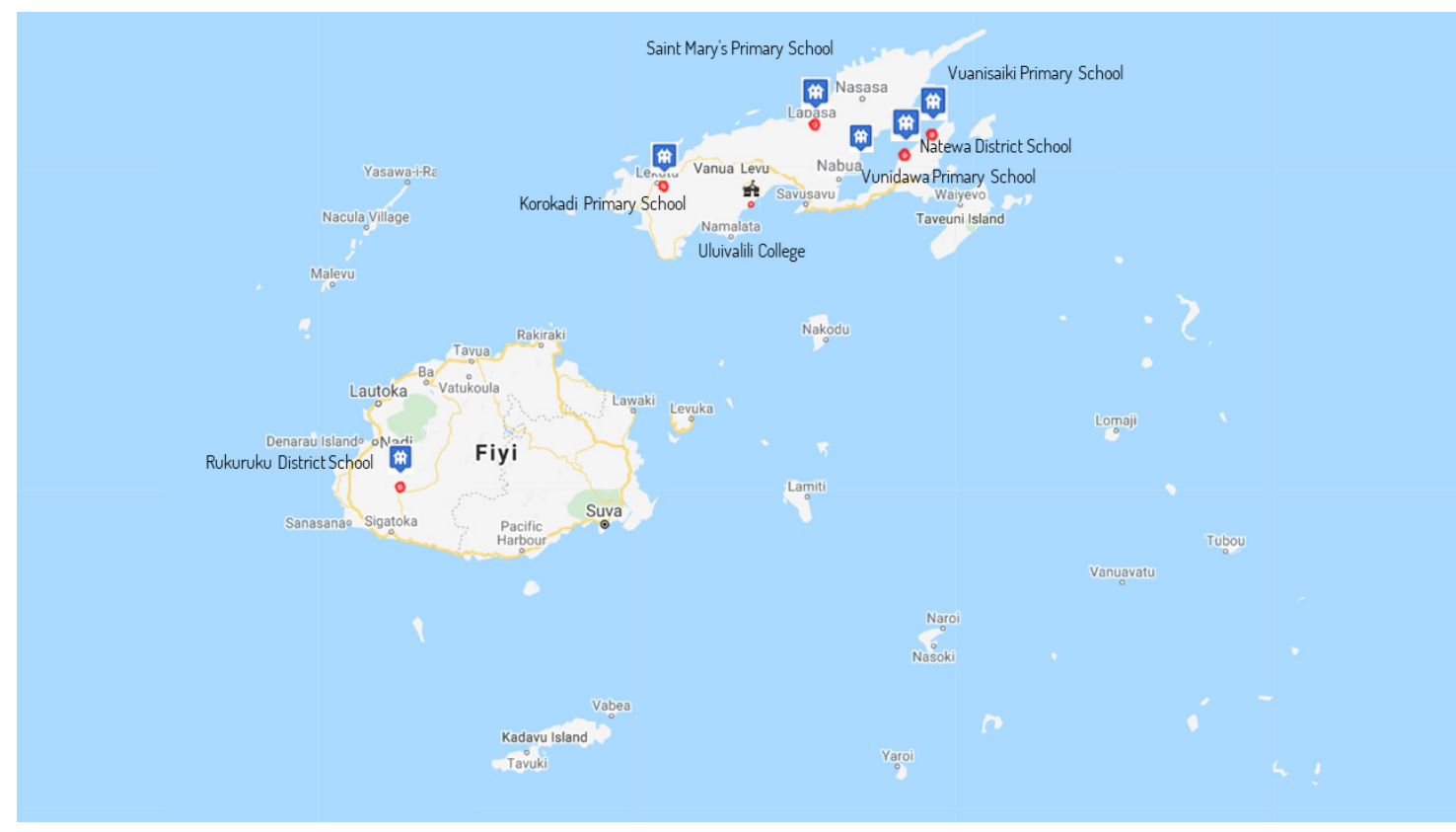

Figure 2. Map showing the participating schools in Fiji.

Fiji is an island country in an archipelago in the Pacific Ocean. The archipelago consists of 300 islands covering a territory of 3,000,000 km². Fiji is $2100 \mathrm{~km}$ from Australia and has a population of 893,700 people; $55.9 \%$ live in urban areas and $44.1 \%$ in rural zones. The nation has four administrative divisions, which are subdivided into 14 provinces: (1) Central Division: Naitasari, Namosi, Rewa, Serua, Tailevu, and Suva, the capital; (2) North Division: Bua, Cakaudrove, Macuata, and Labasa; (3) Southern Division: Kadavu, Lau, Lomaiviti, and Levuka; (4) Western Division: Ba, Nadroga-Navosa, Ra and Rotuma.

As for the weather, all the districts receive the most rain in the hurricane season (November to March), which is experienced every two years. While rainfall reduces in the East of the largest islands from April to October, there is still an annual average of approximately 120 inches $(3000 \mathrm{~mm})$ per year. However, in the West, the annual rainfall approaches only 70 inches (approximately $1800 \mathrm{~mm}$ ), a strong contrast in the weather conditions between East and West, and, therefore, a marked difference in agriculture.

More than a quarter of the population is under the age of 15 , and another quarter is 15 to 29 years old [35]. The government administers the Fiji Educational System, but local committees administer most schools. The Ministry of Education, Heritage, and Arts (MEHA) in Fiji seeks to subsidize educational costs to make it affordable for all; however, school fees and transportation costs in rural areas can be prohibitive for some students [35].

Primary education is compulsory and covers grades 1 to 6 or $1-8$; the latter includes two years of middle education. Secondary education consists of grades 6 and 7; once completed, the student passes to tertiary education. Some high schools offer two years of vocational or technical education that prepares students for the labor market. There are also private vocational schools that offer technical education. There are three institutions of higher education and two institutions that belong to MEHA that train the primary and secondary school teachers [36]. According to MEHA data [37], there are currently 13,500 primary and secondary teachers in Fiji, 148,609 elementary school students, 
and 69,053 high school students. In 2013, 560 rural primary schools were reported, of which 38\% are in very remote areas and are disadvantaged by the lack of communication and transport [38].

\section{Method}

The SolarSPELL project was done as a pilot project in Fiji, introducing the climate change issues in rural schools and training teachers and volunteers to integrate these contents and resources into their teaching. After implementing this pilot, the results were evaluated to see the impact it had on these schools. The purpose of this evaluation was to generate evidence and knowledge about the results of implementing climate change content and lesson plans in the digital library, and to determine whether teachers had begun to incorporate this information into their pedagogy. The project was carried out by Arizona State University in collaboration with Tecnologico de Monterrey, Leuphana University, Guam University, the Kamehameha Schools, Fiji's Ministry of Education, Heritage, and the Arts, and Fiji Peace Corps.

This research observed a case study methodology that describes the impact SolarSPELL had on the teaching-learning process regarding climate-change issues in seven schools located in rural Fiji. The case study approach is considered appropriate because it facilitates investigating a particular case to understand the problem in depth with the data collected in the study [39]. For Yin [40], the case study may include both qualitative and quantitative instruments; this study used quantitative instruments and descriptive statistics in the analysis, which was triangulated with answers to open-ended questions on topics about the use of SolarSPELL and its contribution to teaching climate change topics.

\subsection{Sample}

The sample consisted of seven school principals and 62 teachers and volunteers (who mainly serve as teachers) from the seven schools that were visited by the research team (Figure 3), which are located in the provinces of Cakaudrove, Nadroga-Navosa, Bua, and Macuata; they were selected by a convenience sampling technique [41].

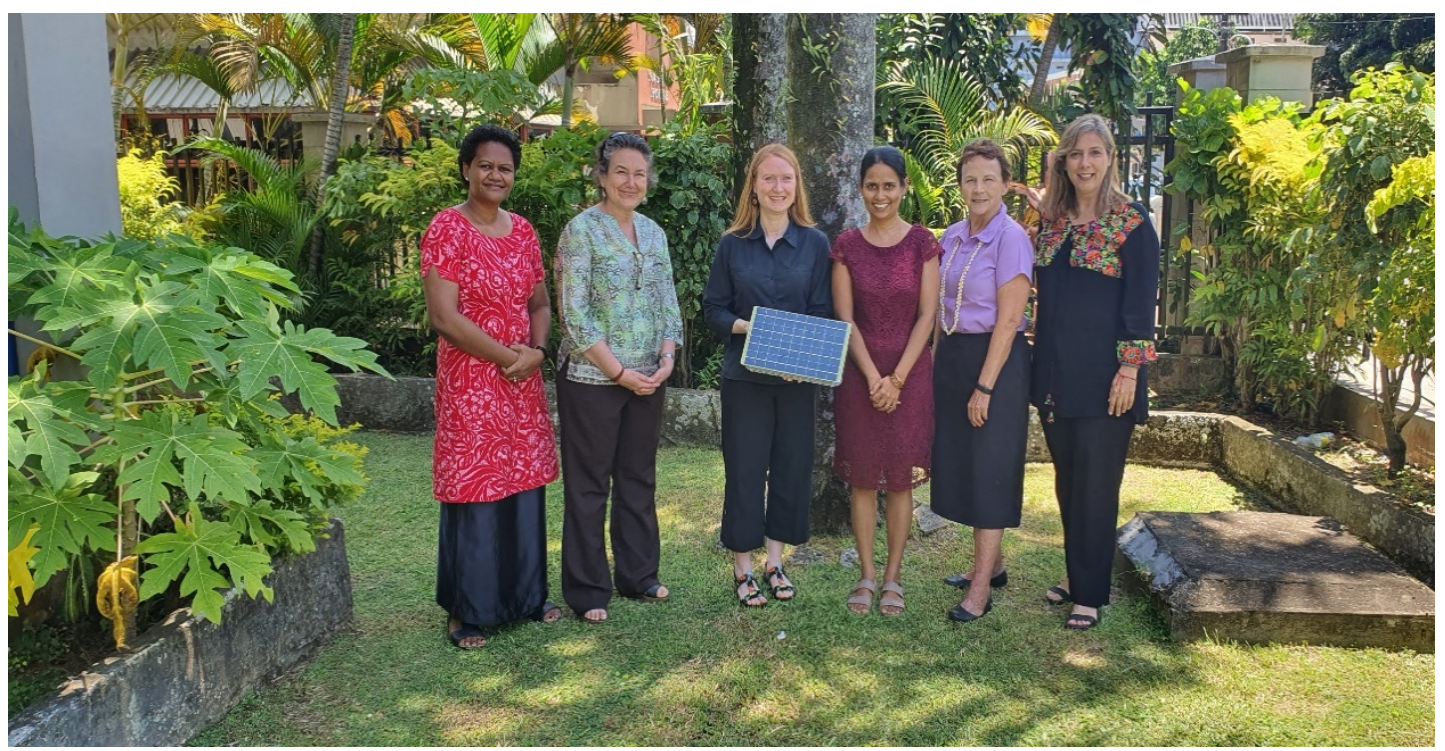

Figure 3. Research team at the Ministry of Education, Fiji.

\subsection{Instruments}

In order to understand the impact that SolarSPELL had on the teaching-learning process on climate change issues in schools located in rural areas of Fiji, five instruments were applied that are part of the DIAPASON, a battery of quantitative and qualitative research instruments focuses on the assessment pedagogic quality of the educational innovation resources. The main research instrument 
of DIAPASON is composed of a set of pedagogic quality indicators that collect information of the following factors: (a) pedagogical; (b) functional; (c) technological; and (d) time [26]. The other research instruments collect data are: (1) Teachers, (2) Librarians, (3) Schools, and (4) Community.

These instruments were used to measure the impact on innovative educational projects, and they were applied personally with a response rate of $100 \%$. After returning home from the research trip, the collected data were inputted into the SurveyMonkey tool for analysis. This article presents the results of the teachers and schools research instruments to measure the impact of the SolarSPELL library on the teaching-learning process and to generate evidence of their capacity to promote the school's transformation.

For the analysis, the descriptive quantitative measures used are percentages and frequency distribution. The closed questions were measured with yes/no questions and with a Likert scale of 4 points. The main purpose of the open-ended questions was to link this information to the closed questions. The answers to these questions were grouped by topic to determine the participants' experiences with the SolarSPELL library and we sought relationships within the participants' answers. We performed an inductive analysis to identify relevant quotes that would support the quantitative data to triangulate the information $[6,40]$. Triangulation was used to test the validity and reliability using data collected from different sources to corroborate the information [40]. Additionally, we considered these collected data important to add voice to the study, so we used quotes considered representative of the views of the majority of the respondents in the analysis and discussion sections. The research instruments collected information on the topics outlined below.

\subsection{Characteristics of the Schools}

This questionnaire consists of 35 items asking about:

- General information about the school: Three open questions to put the school name, city, and province.

- School Features: A closed question about its educational grade levels and three open questions about the number of students, teachers, and classrooms.

- School facilities: Seven yes/no questions to determine if the school had electricity, internet, computer equipment, television, and DVD, among others. There were also questions establishing how many computers and tablets were available.

- Classrooms: Three open and two yes/no questions on aspects such as the average number of students per classroom, the percentage of students with tablets, if they have computer equipment, desks, internet, and a library.

- Education: Four yes/no questions about the subjects studied in school, whether the issues of climate change and sustainable development are covered in the classes, and whether clean energy is used in the school.

- Library: 11 yes/no questions about the library resources, if there was a librarian, the number of hours students stayed in the library, the number of bibliographic resources, if ebooks were available, and if there were resources related to climate change and sustainable development.

- Resources available on climate change and sustainable development: one last open question about the school's resources about these topics.

\subsection{Impact of the SolarSPELL Library}

This instrument had 45 items with a Likert scale of four points asking about:

- School information: Three open questions about the school name, city, and province.

- Teacher/volunteer data: Two open questions about name and age and one closed question about gender.

- The practice of the teacher or volunteer: Seven closed questions asking the grade levels the teachers taught, the number of students per classroom, their opinions about the number of students, 
the characteristics of the students, and the time students spent in class, the main topics studied in class, and the quality of the textbooks.

- Classroom Features: Three closed questions about whether students and the teacher have desks and a library. Three open questions about the percentage of students with tablets, notebooks, and computers.

- Teaching climate change at school: Five closed questions about whether the topic is taught, whether the teacher is concerned about the subject, whether he/she has the knowledge to teach on these topics, whether he/she has sufficient bibliographic resources, and whether he/she has received training on the topics.

- School library: Five closed questions about the library and their opinion on the resources it has, if there was a librarian, whether the students use the library, and whether it has materials related to climate change.

- SolarSPELL Program: Twelve closed questions about the use of SolarSPELL, the training the teacher has received, the time spent on it, and its functionality in the teaching of climate change and sustainable development, the time students spend using it, and whether other members of the community used it. Three open questions about how SolarSPELL is considered in their planning, what a typical day using SolarSPELL is like, its most popular content, and the contents that the teacher would like to find.

- An open question for the teacher to make additional comments about the resources available to teach climate change.

\section{Results}

The results of the applications of the instruments are described below.

\subsection{Characteristics of the Schools}

\subsubsection{School Features}

Seven principals answered the questionnaire about the characteristics of the following schools: Rukuruku District School, Korokadi Primary School, Vunidawa Primary School, Natewa District School, Saint Mary's Primary School, Vuanisaiki Primary School, and Uluivalili College. This instrument was applied to understand the school environment and the facilities that the school had.

The results revealed that three of the schools provided preschool and primary education, three only primary education, and one secondary education. The average number of teachers per school was seven, with an average of 120 students per school and seven classes on average per teacher. The average number of students per class was 23 students.

\subsubsection{School Facilities}

All the schools surveyed had electricity; five had electricity all the time; one, $50 \%$ of the time, and the other only $25 \%$. Six schools reported having access to the Internet (which, according to in-depth interviews carried out at the schools, was often clarified to mean internet access to the administrative offices); three had it $100 \%$ of the time; one, $50 \%$ of the time, and two, $20 \%$ of the time. This internet access is not necessarily available to the classrooms themselves, which is demonstrated by the percentages of internet access in the classrooms detailed below. Of all classrooms, $57.14 \%$ had a projector (4 schools); none had a TV or DVD player. Two schools reported having 90 to $100 \%$ of computers working ( 7 on average); two schools, $50 \%$ ( 3 on average), and one had no computer.

One school has 25 tablets/notebooks, of which $88 \%$ function (22 tablets for 152 students); another school reported 20 tablets/notebooks, all working (20 tablets for 89 students); one had nine tablets (50\% working, 4.5 tablets for 78 students). Three schools reported having four each (in two of them, all are working, and in the other, only one), so, in one school, there were four tablets for 113 students; in another, four tablets for 91 students, and, in another, one for 80 students. One school reported having 
none. One school reported that $16 \%$ of the students had tablets and the others, none. The tablet/student distribution is shown in Figure 4.

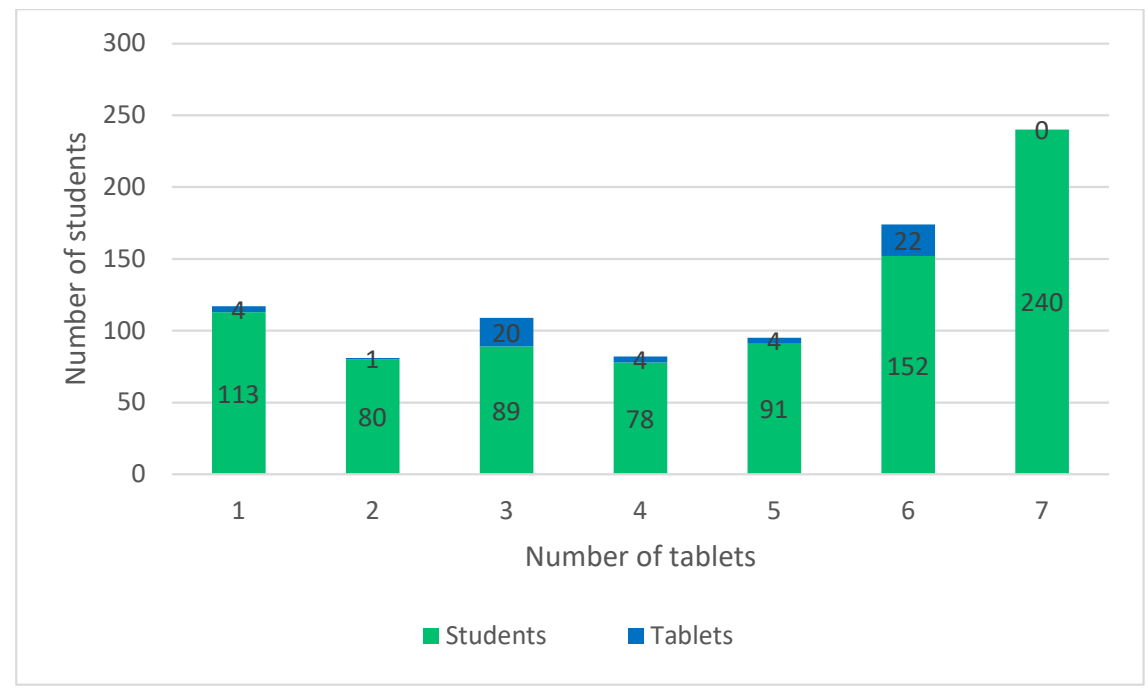

Figure 4. Number of students and tablets available per school.

\subsubsection{Educational Space}

Regarding the Internet in the classroom, one school indicated that it had the Internet $100 \%$ of the time, another $50 \%$ of the time, and the other five schools did not have the internet at any time. Of all respondents, $71.43 \%$ indicated that classrooms had a library space and that the main topics taught were English $(85.71 \%)$, climate change $(71.43 \%)$, literacy $(71.43 \%)$, crafts $(57.14 \%)$, and sustainable development (42.86\%) (Figure 5). All the schools offered computer science classes, $85.71 \%$ taught climate change issues, and all indicated teaching about sustainable development. $57.14 \%$ of the participants responded that they use clean energy.

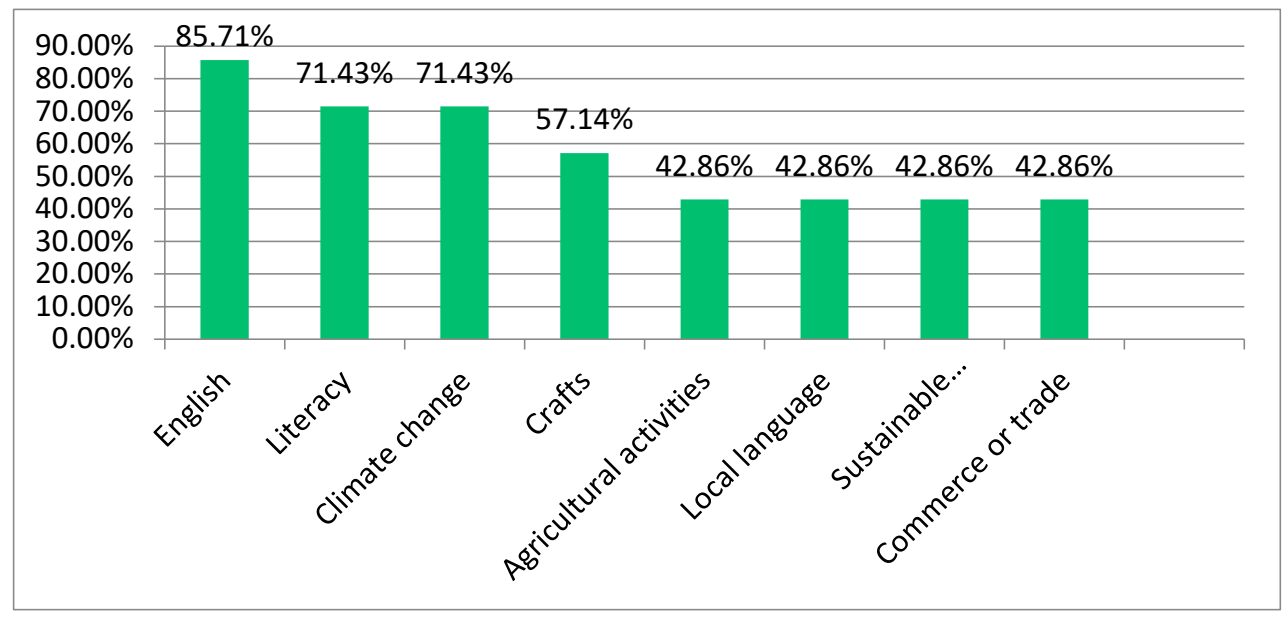

Figure 5. Main topics taught at schools.

\subsubsection{Library Space and Available Resources}

All the schools had a library, and three had a librarian (Figure 6). The teachers indicated that the students, on average, use the library $1.20 \mathrm{~h}$ a week. According to $85.71 \%$ of the responses, students do learning activities in the library; none of the libraries offer ebooks, and only one had digital educational resources. Two offered access to a digital library, and six had books related to climate change. Three had books about sustainable development. 


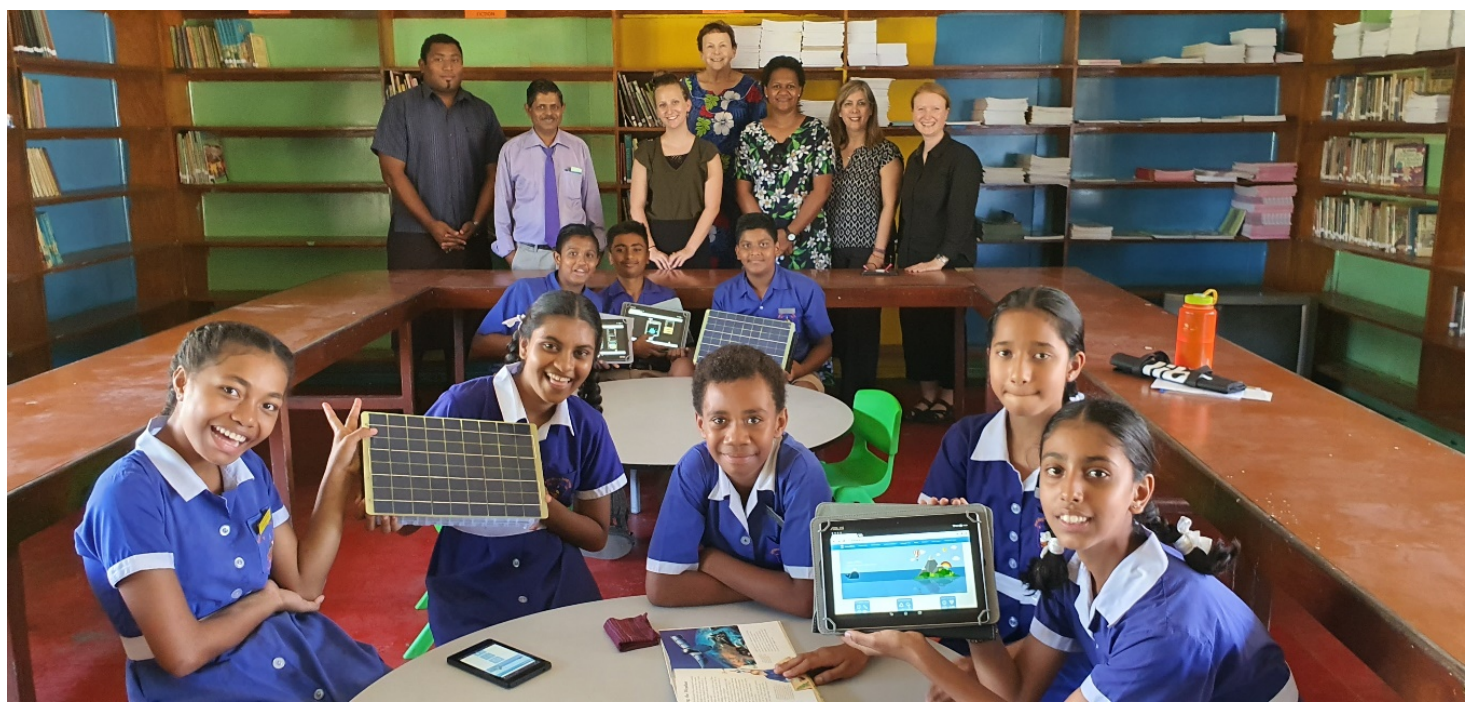

Figure 6. Library space and available resources.

In the last open question that asked about the resources needed for teaching and learning about climate change and sustainable development, the respondents indicated that they needed more computers or tablets to be donated to the schools. They also described how they are working to have more infrastructure: "The school is still waiting for the computers for the computer class"; "We did have nine learning resources on climate change and sustainable development"; "We have a library almost ready to use"; "In the past, the library room used to be a full-time classroom"; "We received funding from the Ministry of Education to buy resource materials"; "By the end of Term I, 2020, the library will be fully operational with enough resources".

Further, about the usefulness of SolarSPELL and the need for more resources: "Since the school does not have access to the internet, Solar Spell will be the most suitable resource", and "I hope that more climate change content will be loaded."

\subsection{Impact of the SolarSPELL Library}

This instrument was answered by 59 people, of whom 33 were men and 26 were women. The results are presented below.

\subsubsection{Practice of the Teacher or Volunteer}

Of those responding to this questionnaire, $74.58 \%$ work in primary education, $23.73 \%$ in secondary school, and $1.69 \%$ in preschool. $83 \%$ of the respondents considered the number of students in the classroom to be sufficient, and $12 \%$ felt there were too many. About the characteristics of students, $50.85 \%$ responded that they have students of different ages, and $40.68 \%$ have students in different grade levels. In total, 685 students in the surveyed schools were male, and 679 were female.

Most of the teachers felt that the time students spent in the classroom was sufficient (84.48\%) and that this time was mostly spent on learning to read and write $(83 \%)$, followed by studying mathematics $(73.58 \%)$, and then natural sciences (58.49\%). Regarding climate change, $56.60 \%$ indicated that they spend time studying it, and $39.62 \%$ covered sustainable development. $84.21 \%$ indicated that the students receive a textbook package, and $56.90 \%$ think their quality is good.

\subsubsection{Characteristics of the Classroom}

Regarding equipment, $94.64 \%$ of the teachers responded that they had their own desk, $79.3 \%$ that students also have a desk and can work individually, $92 \%$ indicated that no student has a tablet or notebook, and 73\% do not have a smartphone. Notably, 100\% responded that the school has a library. 


\subsubsection{Teaching about Climate Change at School}

When asked if the school teaches about climate change, $98 \%$ said yes. $83 \%$ indicated that they were deeply or sufficiently concerned about student learning on this topic. $79 \%$ believed that they were very prepared or sufficiently prepared to teach climate change issues (Figure 7). 51.67\% believe that they have few bibliographic resources related to these topics, and only $1.67 \%$ considered them sufficient. In terms of the training they receive on climate change issues, $44 \%$ indicated that they rarely receive it, and only $28.81 \%$ answered that sometimes they did.

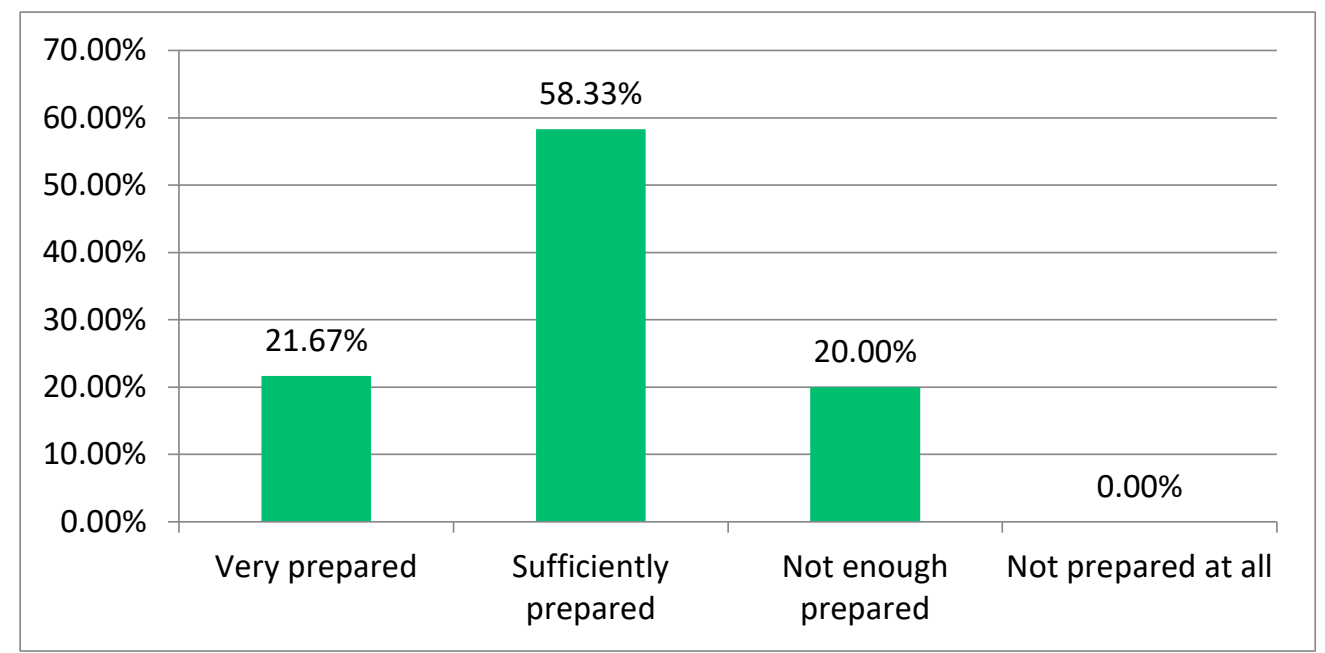

Figure 7. Teacher preparation for climate change issues.

\subsubsection{School Library}

All the teachers responded that the school has a library (100\%), but only $24.14 \%$ reported having a librarian. Most indicated that students spend less than an hour a week in the library and $81 \%$ indicated that they do it to spend their time performing learning activities. Regarding the library's materials on climate change, $47 \%$ considered it poor, and $42 \%$ that it is good; only one answered that the material was excellent.

\subsubsection{SolarSPELL Program}

Regarding SolarSPELL, $83 \%$ of the respondents indicated that they had received excellent or good training on its use. 100\% reported having had SolarSPELL for a year or less than a year. Additionally, $85 \%$ have used the SolarSPELL library in their teaching activities for one to seven months. The teachers reported that the SolarSPELL helped them teach math subjects $(61.4 \%)$, reading $(59.65 \%)$, climate change $(56.14 \%)$, natural sciences $(50.88 \%)$, writing $(38.60 \%)$, and sustainable development $(31.58 \%)$. The distribution is shown in Figure 8.

$54.55 \%$ of respondents indicated that they used SolarSPELL to self-train on climate change issues, $47.27 \%$ on mathematics, $43.64 \%$ on natural sciences, and $40 \%$ on sustainable development. $65.52 \%$ used it to teach about climate change issues, and $55.35 \%$ reported using it to teach about sustainable development. Teachers indicated that they integrated SolarSPELL into their classes, especially for the videos and the pdf documents contained in the library, as well as using it for research where the students could explore topics. For example, two of the teachers interviewed commented, "I usually use SolarSPELL to find activities that I can incorporate into my lessons. Occasionally, I have students watch a video that is found on it." The other commented, "Lesson notes are derived from SolarSPELL based on certain topics. The educational videos shown to students from SolarSPELL relate to the topics they are studying." They also use other resources that the solar library has: "I use the 'Reading Resources' in SolarSPELL to work on reading interventions. I also incorporate the 'Climate Change' themes from the readings. I also use the 'Wiki' resource for upper primary research". 


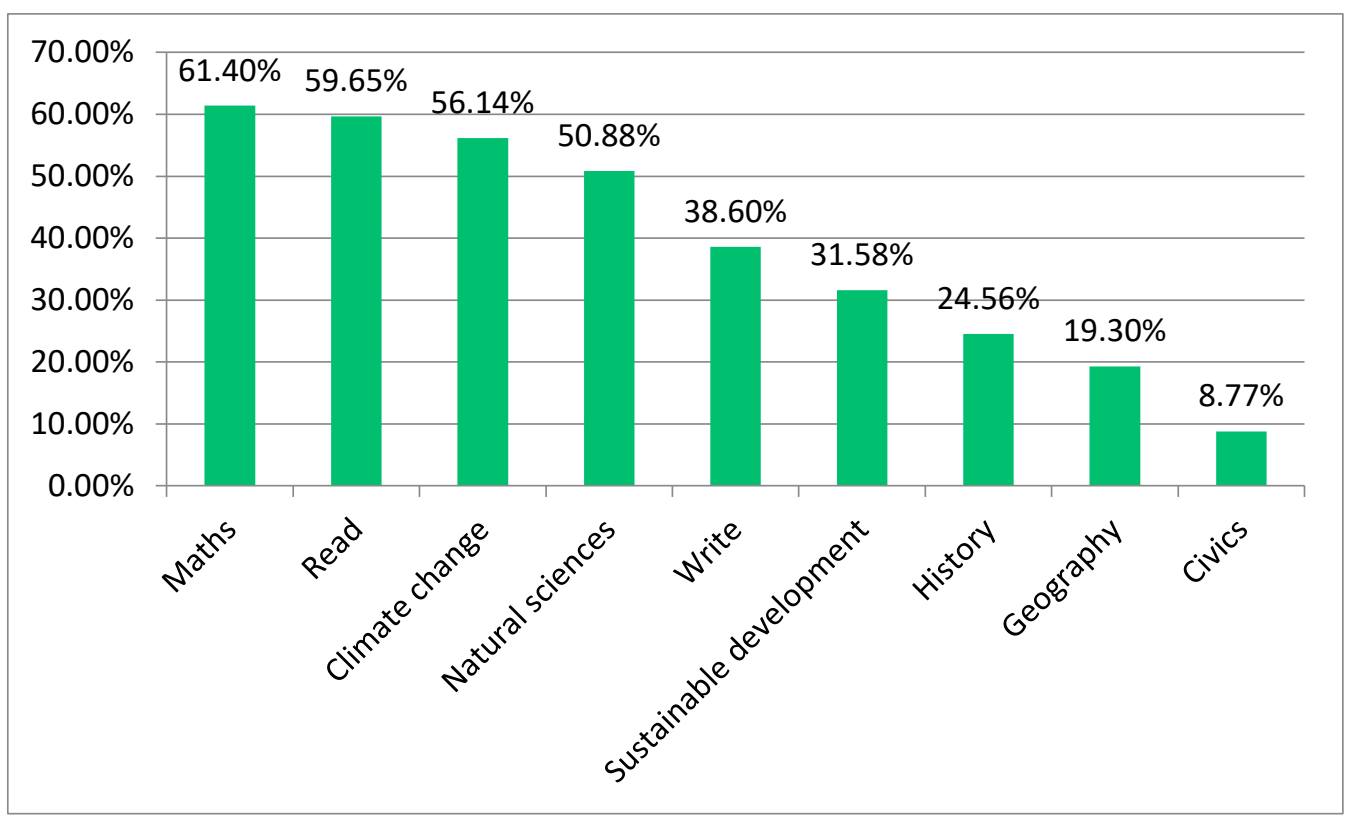

Figure 8. Topics studied using SolarSPELL.

When asked to describe a typical day in the use of the SolarSPELL, the teachers responded that the digital library served to motivate the students and that they were happy to use the tool. For example, they made comments such as "The SolarSPELL days are always the ones where the children are eager, it is like a big day for them to discover something new"; "We also use it as an additional reward system for well-behaved classes"; "Students get excited when we tell them to bring their gadgets to school. By this, they know that they will get to use the SolarSPELL"; "There were lots of excitement, the writing of notes, and just 'oohs $\mathcal{E}$ aahs and Alrights!!"”

They also reported that they use SolarSPELL to obtain support material for their classes, especially the videos and subject material it contains and that the students use it to research and explore more about the topics. As they mentioned: "Science videos and content are downloaded from SolarSPELL for students to view; conversational videos are downloaded, and also videos on ways to teach mathematics"; "I go on the SolarSPELL unit with a lesson in mind already and then pull out the content related to the lesson." It has also been useful to students who have a problem, especially with reading. "I'm currently working with five non-readers in the year 6 level. After teaching the phonics (Jolly Phonics from SolarSPELL) and blending, I tried giving them the Easy Readers again from the SolarSPELL, which they loved reading."

They also often face equipment limitations when they use it, so the teachers must do so on a limited basis. However, they recognize that it is a very valuable tool, especially when there is no internet connection, as one commented, "Science videos are very useful since internet connectivity is sometimes slow."

On the most popular topics, the teachers responded that those are phonics, climate change, human body systems, and sciences. They also would like to find local topics related especially to the Fijian (or iTaukei) and Hindi languages, in addition to the history of the Pacific countries and topics about local culture and local authors, among others.

While the teachers find the SolarSPELL very useful in motivating their students and supporting their classes, in the question of how often they use it, $1.69 \%$ used it daily, 32.20\% used it several times a week, $27.12 \%$ used it once a week, $3 \%$ once a month, and $33.9 \%$ not often (Figure 9). About this, respondents indicated: "What I want on the SolarSPELL library in our school if we can have access to it throughout our day in our classrooms", and another respondent said: "I think it scares my teachers a little, and very few have looked at the Spell outside of the 1st session for the Spell." 


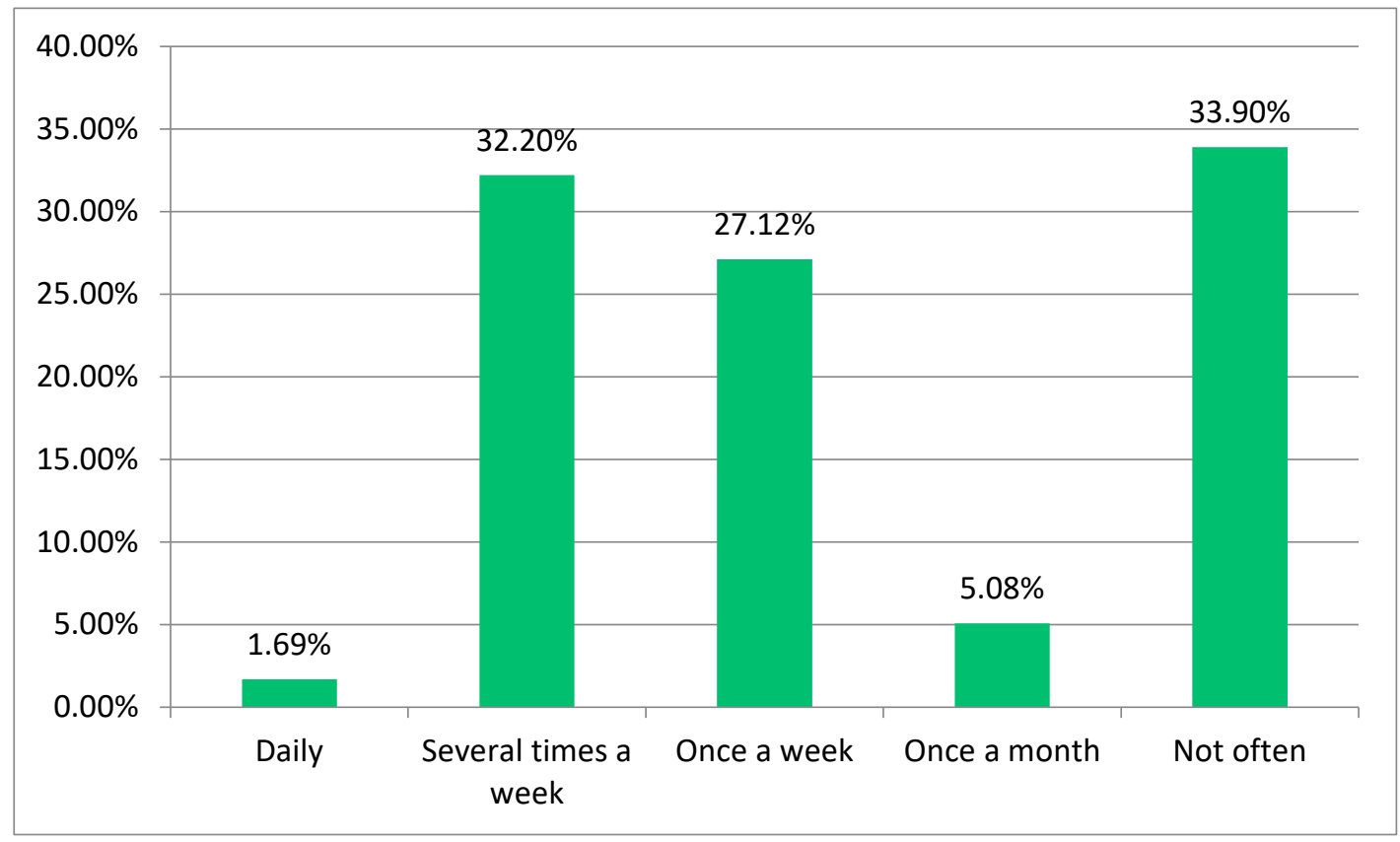

Figure 9. Frequency of use of SolarSPELL in learning activities.

For self-training, 30.51\% used it several times a week, $29 \%$ once a week, and $32.20 \%$ did not use it for self-training often. In the question about how often SolarSPELL is used in their school/workplace, $10.34 \%$ of the teachers indicated daily, $37.93 \%$ several times a week, $25.86 \%$ once a month, and $13.79 \%$ not often.

The respondents indicated that for connecting to the SolarSPELL, their devices were tablets $(84.75 \%)$, laptops $(71.19 \%)$, and smartphones $(66.10 \%)$. The main form of storage was in the principal's office $(45.76 \%)$, in a designated office (37.29\%), or in the school $(25.42 \%)$.

In the last question asking for additional comments, most responses were aimed at getting the SolarSPELL to include more climate change content and videos on local Fiji-related topics, as some commented, "More resources about how climate change affects Fiji would be great!" "I would like to see more resources relevant to the community or a case study of the Fijian communities that experienced it." In addition to needing more tablets so that the students can connect, the teachers report that they see SolarSPELL as a necessary tool because they do not have the conditions to access those resources otherwise: "The SolarSPELL is a great asset to our school as we don't have regular access to electricity and the internet."

\section{Discussion}

In order to answer the research question, two data collection tools were implemented that generated information about what the impact is of SolarSPELL on the process of teaching about climate change in Fijian schools located in rural communities.

From the surveys carried out, it can be observed that there are limitations in electricity and internet resources in the schools, and, although they have these resources, they do not have them all the time, nor in all the school spaces. Therefore, resources like SolarSPELL, supported by clean energy, help students access newer and more up-to-date resources [12]. The use of ICTs also allows for addressing inequalities in digital life, enabling people without prior access to these resources to develop socio-technical and digital literacy skills [11]. Another limitation identified during the study is the insufficient number of electronic devices such as tablets and smartphones per student that the schools have, resources that are necessary to use the network and the digital library, causing the use of this resource to be less frequent in the teachers' lesson plans than may have otherwise been the case had there been sufficient devices. 
Regarding education for climate change, one challenge is understanding the complexity of the subject, and having appropriate resources for its teaching is also needed [24]. Nonetheless, SolarSPELL became a resource that the teacher respondents considered appropriate to support their classes, taking into account the multimedia materials found in the resource. Because the teachers and volunteers surveyed consider that they have limited access to literature or training on the topic of climate change, they use SolarSPELL to train themselves on these issues. On improving results, as a result of having this resource, one of the teachers commented:

The most remarkable outcome for my school is that last year, at the end of the school year, we had $100 \%$ positive results on external exams. When I first came to my school, for the past three years, the overall scoring for this external exam was $29 \%$. In my second year, we managed to move it up to $54 \%$. However, last year we got $100 \%$ ! Thanks to SolarSPELL, my children have access to the world.

The teachers indicated that the students are very happy when they use the SolarSPELL, so it also becomes a motivational tool for students to learn, who find the videos and resource materials on the topics they are studying to be interesting, especially those on climate change, one of the most popular topics sought in the digital library. The respondents also stated that they wanted to find topics related to their culture, languages, and resources, especially in the vernacular languages. It is important for technology to have an impact and make relevant contributions to development; it must address local needs and be designed to meet them [13].

SolarSPELL, as a pedagogical resource for the teaching of climate change, is considered to have an impact on the following aspects [28]:

1. On the social appropriation of knowledge: the resources contained in the digital library allow teachers/volunteers and students to access information related to topics relevant to the study of climate change in their environment, and, also, it becomes a motivational tool for the teaching/learning process. As the respondents commented: "Especially with climate change- they love to watch the short clips from the SolarSPELL. They love it because it's more to their context, to the Pacific Islands nations"; "I was very pleased to know that there is a lot of content on climate change. For Fiji, it's the first time I have seen information about climate change. We just know where we are in our context." Furthermore, for teachers, it is a training tool, as they mentioned using it to self-train, obtain material for study plans, and incorporate them into their classes.

2. On citizen science: The work done by the professor-researchers and the communities involved in the SolarSPELL project promotes the democratization of knowledge in vulnerable and isolated areas that would not otherwise have access to these resources, as the respondents mentioned: "The SolarSPELL introduces something that the school has never had before, namely, an addition of new resources that can also be updated regularly. Just having up-to-date resources available to the students is an invaluable resource that may otherwise have not been available to them."

3. On social innovation: the educational resources found in SolarSPELL and their application to the problems of climate change that are lived in this context can also generate awareness so that the students and the community become involved in taking actions together to resolve the problems. As one of the respondents mentioned about the change in attitude:

Climate change is really good [as a topic] for them because it is real. We are living beside the ocean, and it does not feel real until you become a part of it in some way. At times, when there is a very high tide, the village here floods. So, some of the topics interest them and open up their minds. Whatever the students learn in the school, they are going back and bringing it to their villages with them. I see that their attitude is changing. Before, they came to school and threw things in the rubbish dump and burned it. Now, they hardly do those things. Now they try to reuse things as much as possible. So, it changed their mindset, looking at those videos on climate change. 


\section{Conclusions}

The results that we found show that the use of the SolarSPELL digital library provides access to educational and technological resources in rural areas that have limitations in resources as basic as electricity and internet access. SolarSPELL has a significant impact on the schools in these vulnerable areas of Fiji. The SolarSPELL users have used the library for teacher support and as motivation for students to learn, not only about climate change but also other topics. SolarSPELL provides up-to-date, context-appropriate multimedia resources, which teachers also use for self-training. Yet, it was also found that the limited number of electronic devices available to connect to the library made it difficult to use it frequently, particularly with the students.

These results also confirm that the SolarSPELL digital library generates social impact by facilitating the inclusion of vulnerable communities and removing barriers to their participation. The study of climate change and sustainable development issues will allow us to continue to develop the competencies that favor not only creating awareness of these problems but also changing the attitudes and behaviors of the citizens. The teacher training supported by this project has allowed them to incorporate this approach into their classrooms and adapt it to the local contexts.

This study has theorical and practical implications. Theorical implications, on one hand, are the presentation of good practices that promote education and knowledge acquisition in vulnerable areas and that can impact the teaching-learning process in these schools. Regarding the practical implications, this study provides information on the reality of the schools analyzed in Fiji and pays attention to the needs of teachers and students in this context. This information can be useful for international and national organizations that promote tools such as the SolarSPELL to address the need for educational innovations that favor inclusion in marginalized regions.

For future studies, we suggest continuing to deepen the analysis of the results presented in this research about how school characteristics can affect the success of the SolarSPELL initiative. We recommend continuing research on the potential applications of SolarSPELL and considering the suggestions from teachers and volunteers about the topics that need to be included, such as native languages, which will increase the socio-ecological impact of the resources made available by this tool. We also recommend continuing the development of strategies that involve all educational actors so that the implementations of SolarSPELL increase. To this end, the SolarSPELL team scheduled a visit with the Ministry of Education while in Fiji and met with the Acting Permanent Secretary (pictured above in Figure 3). At this meeting, Secretary Kiran voiced her support for continuation of the SolarSPELL initiative within Fiji and recommended an even closer working relationship between the Fiji Ministry's Curriculum Development Department and the SolarSPELL team at ASU. To give a specific, concrete example, one plan moving forward is for the SolarSPELL library to map (climate change and other) lesson plans to the existing Fijian curriculum and textbooks, by grade level and subject area. This will be done to ensure that the SolarSPELL library's content will best meet the needs of Fiji's teachers.

Author Contributions: Conceptualization, L.H. and M.G.G.Z.; methodology, M.G.G.Z. and L.A.d.l.G.; validation, L.H. and M.G.G.Z.; formal analysis, L.H., M.G.G.Z. and L.A.d.l.G.; investigation and evaluation, L.H., M.G.G.Z. and L.A.d.l.G.; writing-original draft preparation, L.H. and M.G.G.Z.; writing-review and editing, L.H., M.G.G.Z. and L.A.d.1.G.; funding acquisition, L.H., M.G.G.Z. and L.A.d.1.G. All authors have read and agreed to the published version of the manuscript.

Funding: Funding for the fieldwork that informed this article was provided by a grant from the Global Consortium for Sustainability Outcomes.

Acknowledgments: The authors acknowledge the technical support of Writing Lab, TecLabs, Tecnologico de Monterrey, Mexico, in the production of this work.

Conflicts of Interest: The authors declare no conflict of interest. 


\section{References}

1. UNESCO. Objetivos de Desarrollo Sostenible. 2020. Available online: https://www.un.org/sustainabledevelopment/ es/education/ (accessed on 3 July 2020).

2. Lakkala, S.; Uusiautti, S.; Kyrö-Ämmälä, O.; Grönfors, P. Students' social self-image and engagement with studies within the classroom: A qualitative multi-method research on teachers' pedagogical activities in inclusive education. Int. J. Whole Sch. 2020, 16, 35-60.

3. Óskarsdóttir, E. Constructing Support as Inclusive Practice: A Self-Study. Ph.D. Thesis, University of Iceland, Reykjavík, Iceland, August 2017.

4. Echeita, G. Educación inclusiva: Sonrisas y lágrimas. Aula Abierta 2017, 2, 17-24. [CrossRef]

5. Leal Filho, W.; Eustachio, J.H.P.P.; Caldana, A.C.F.; Will, M.; Lange Salvia, A.; Rampasso, I.S.; Anholon, R.; Platje, J.; Kovaleva, M. Sustainability leadership in higher education institutions: An overview of challenges. Sustainability 2020, 12, 3761. [CrossRef]

6. Portuguez Castro, M.; Gómez Zermeño, M.G. Challenge based learning: Innovative pedagogy for sustainability through e-learning in higher education. Sustainability 2020, 12, 4063. [CrossRef]

7. Hui, N.; Vickery, E.; Njelesani, J.; Cameron, D. Gendered experiences of inclusive education for children with disabilities in West and East Africa. Int. J. Incl. Educ. 2018, 22, 457-474. [CrossRef]

8. Clouder, J.; Cawston, J.; Wimpenny, K.; Mehanna, K.; Hdouch, Y.; Raissouni, I.; Selmaoui, K. The role of assistive technology in renegotiating the inclusion of students with disabilities in higher education in North Africa. Stud. High. Educ. 2018, 44, 1344-1357. [CrossRef]

9. Carew, M.; Deluca, M.; Groce, N.; Kett, M. The impact of an inclusive education intervention on teacher preparedness to educate children with disabilities within the Lakes Region of Kenya. Int. J. Incl. Educ. 2019, 23, 229-244. [CrossRef]

10. Armey, L.E.; Hosman, L. The centrality of electricity to ICT use in low-income countries. Telecommun. Policy 2016, 40, 617-627. [CrossRef]

11. Hosman, L.; Pérez Comisso, M. How do we understand "meaningful use: Of the internet? Of divides, skills, and socio-technical awareness. J. Inf. Commun. Ethics Soc. 2020, 18, 1-19. [CrossRef]

12. Hosman, L.; Walsh, C.; Perez Comisso, M.; Sidman, J. Building online skills in offline realities: The SolarSPELL initiative. First Monday 2020, 25. [CrossRef]

13. Hosman, L.; Armey, L. Taking technology to the field: Hardware challenges in developing countries. Inf. Technol. Dev. 2017, 23, 648-667. [CrossRef]

14. Chen, H.; Ling, L.; Ma, Y.; Wen, Y.; Gao, X.; Gu, X. Suggestions for chinese university freshmen based on adaptability analysis and sustainable development education. Sustainability 2020, 12, 1371. [CrossRef]

15. UNESCO. Mudança Climática em Sala de Aula: Curso da UNESCO Para Professores Secundários Fundamental II e Ensino Médio) Sobre Educação em Mudança Climática e Desenvolvimento Sustentável (EMCDS); United Nations Educational, Scientific and Cultural Organization: Brasilia, Brazil, 2014.

16. Takala, A.; Korhonen-Yrjänheikki, K. Una década de educación finlandesa en ingeniería para el desarrollo sostenible. J. Sustain. Alto. Educ. 2019, 20, 170-186.

17. Geli de Ciurana, A.; Leal Filho, W. Education for sustainability in university studies: Experiences from a project involving European and Latin American universities. Int. J. Sustain. High. Educ. 2006, 7, 81-93. [CrossRef]

18. Leal Filho, W. About the role of universities and their contribution to sustainable development. High. Educ. Policy 2011, 24, 427-438. [CrossRef]

19. Balakrishnan, B.; Tochinai, F.; Kanemitsu, H. Perceptions and Attitudes towards Sustainable Development among Malaysian Undergraduates. Int. J. High. Educ. 2020, 9, 44-51. [CrossRef]

20. Istenic Starcic, A.; Terlevic, M.; Lin, L.; Lebenicnik, M. Designing learning for sustainable development: Digital practices as boundary crossers and predictors of sustainable lifestyles. Sustainability 2018, 10, 2030. [CrossRef]

21. Iyer-Raniga, U.; Andamon, M. Transformative learning: Innovating sustainability education in built environment. Int. J. Sustain. High. Educ. 2016, 17, 105-122. [CrossRef]

22. Mahatma Gandhi Institute of Education for Peace and Sustainable Development. Textbooks for Sustainable Development: A guide to Embedding; UNESCO MGIEP: New Delhi, India, 2017. 
23. Leal Filho, W.; Morgan, E.A.; Godoy, E.S.; Azeiteiro, U.M.; Bacelar-Nicolau, P.; Veiga Ávila, L.; Mac- Lean, C.; Hugé, J. Implementing climate change research at universities: Barriers, potential and actions. J. Clean. Prod. 2018, 170, 269-277. [CrossRef]

24. Tibola da Rocha, V.; Londero Brandli, L.; Locatelli Kalil, R. Climate change education in school: Knowledge, behavior, and attitude. Int. J. Sustain. High. Educ. 2020, 21, 649-670. [CrossRef]

25. U.S. Fish and Wildlife Service. Climate Change in the Pacific Islands. Available online: https://www.fws.gov/ pacific/climatechange/changepi.html (accessed on 3 July 2020).

26. Gómez-Zermeño, M. Digital libraries: Electronic bibliographic resources on basic education. Comunicar 2012, 39, 119-128. [CrossRef]

27. Druin, A. What children can teach us: Developing digital libraries for children with children. Libr. Q. 2005, 75, 20-41. [CrossRef]

28. Díaz-López, L.; Ortiz, J.T.; Contreras, C.-P. Strategies for inclusive and safe education using virtual reality: From the digital library perspective. Digit. Lib. Perspect. 2019, 35, 216-226. [CrossRef]

29. Hosman, L. Improving partnerships: Applying lessons learned to improve partnerships in innovative educational experiences. Partnersh. J. Serv. -Learn. Civ. Engagem. 2014, 5, 24-50.

30. Linzy, K.; Hosman, L. The SolarSPELL Offline Digital Library. Available online: http://library.ifla.org/2106/1/ 205-linzy-en.pdf (accessed on 3 July 2020).

31. Theda, F. Learning Climate Change through a Solar Powered Library. Available online: https://www.accern. net/blog/learning-climate-change-through-solar-powered-library (accessed on 3 July 2020).

32. Kelman, I. Hearing local voices from Small Island Developing States for climate change. Local Environ. 2010, 15, 605-619. [CrossRef]

33. UNISDR. UN Global Assessment Report. 2013. Available online: https://www.preventionweb.net/english/ hyogo/gar/2013/en/gar-pdf/GAR2013_EN.pdf (accessed on 27 July 2020).

34. Johnston, I. Disaster management and climate change adaptation: A remote island perspective. Disaster Prev. Manag. 2014, 23, 123-137. [CrossRef]

35. Macdonald, B.; Foster, S. Fiji. Encyclopædia Britannica. Available online: https://www.britannica.com/place/ Fiji-republic-Pacific-Ocean (accessed on 3 July 2020).

36. UNESCO. World Data on Education. Fiji. Available online: http://www.ibe.unesco.org/fileadmin/user upload/Publications/WDE/2010/pdf-versions/Fiji.pdf (accessed on 3 July 2020).

37. MEHA. Students and Parents. Available online: http://www.education.gov.fj/students-parents/ (accessed on 3 July 2020).

38. Lingam, G.; Lingam, M. Making learning and teaching a richer experience: A challenge for rural Fijian primary schools. Educ. Res. Rev. 2013, 8, 2160-2168.

39. Stake, R. Investigación Como Estudio de Casos; Morata: Madrid, Spain, 2007.

40. Yin, R. Case Study Research; Sage: Thousand Oaks, CA, USA, 2009.

41. Otzen, T.; Manterola, C. Técnicas de Muestreo sobre una Población a Estudio. Intern. J. Morphol. 2017, 35, 227-232. [CrossRef]

(C) 2020 by the authors. Licensee MDPI, Basel, Switzerland. This article is an open access article distributed under the terms and conditions of the Creative Commons Attribution (CC BY) license (http://creativecommons.org/licenses/by/4.0/). 